\title{
The social and environmental impact of hybrid cars
}

\author{
Nadia Asima \\ adnan Ali Al Bimani \\ Ahmed Said Mohammed Al \\ Saqri \\ Dr. Maria Teresa Matriano
}

\author{
MIDDLE EAST COLLEGE \\ Middle East College \\ Middle East College \\ Middle East College
}

\begin{abstract}
Technology is rapidly evolving in this $21^{\text {st }}$ century era. It is a marvel to behold as it makes human lives much easier. With advancement of technology and increase of vehicles and factories, pollution and destruction of natural resources has increased on a huge scale. The study is based on a product substitute, introduced to replace vehicles which run on gasoline, with a hybrid of electric and gasoline vehicles. The objective of this research will be aiming at understanding the effect of hybrid cars on the environment. An analysis of the hybrid cars will be carried out along with evaluating the advantages and disadvantages of said vehicles from the perspective of customers, support and maintenance. The research will also aim on proposing a government policy that must be implemented to regulate the usage of hybrid vehicles. The methodology used for this research will consist of primary sources wherein meetings will be conducted with the company selling such cars or people who own them. Secondary sources will include literature review from research papers and online blogs. With this study, the researchers hope to achieve a clear understanding on the influence of hybrid cars on the environment and individuals, the way hybrid cars operate, its advantages and disadvantages and the proposed government policy that will regulate the impact of hybrid car on environment.
\end{abstract}

\section{INTRODUCTION}

The automobile industry has evolved over the years, advancing it to suit the needs of the current world. The advancements have reached to a level where the vehicles are being built on the grounds of being more ecofriendly, safer and money saver on long term basis. Hybrid cars are one such innovation. It is the new major trend towards which the world is shifting. Combining the forces of a regular engine with an electric motor, hybrids present a more practical option on being safer on the environment as well as saving most of the amount spent on oil refilling's. The project titled 'Evaluating the insides of an hybrid car and the study of its effects on entities' is going to showcase a critical study on what are hybrid cars and the types of it, how the hybrid engine works together and contributes to less pollution as well as a detailed study on batteries contained. A case study will be followed, on Toyota Prius and information from primary sources will be coined together. Results will include the effects hybrid vehicles will have on different aspects, followed by a discussion to show the importance of this analysis and the conclusion.

\section{POLLUTION}

World health organization listed air pollution as the world's most consequential environment health risk, resulting in estimated deaths per year, around 6 million along with countless cases of diseases related to cardio and respiratory system. Michal and his mates mention in their article (Michał Krzyżanowski, Kuna-Dibbert and Jürgen Schneider, 2005), that a huge part of contribution to air pollution is caused by road transport and even the static traffic. Over the years, with increasing population leading to rise in vehicles, a major shift towards hybrid and electric cars is taking place 
for a greener, cleaner and better environment.

\section{TECHNOLOGY INVOLVED IN HYBRID CARS}

Hybrid cars attempt to get the perfect blend of a more advanced internal combustion (IC) along with a very economical electric motor. (Drivingfast.net, 2018)

\section{Types of hybrids:}

Series: The electric motor is in charge here. The gas engine or a generator plays the role of recharging the battery packs of the motor. Since it runs majorly on motor, such cars are better for driving shorter distances within the cities with more stops. The engine is usually held back to be used only for situations that actually requires the car to run more efficiently. This makes the engine smaller and the built of motors bigger since it's the major source. The bigger the size of the motor, the larger the battery it needs, hence adding all together, ends up being more expensive than a parallel hybrid. Example: The BMW i3.

Parallel: Here, both the IC engine and the motor are allowed to work together to power the car. The engine is never switched off here, and it keeps contributing to the car's progress. The gas is provided to the engine by the fuel tank and the batteries are charged using generators. At low power, motor can also be converted to a generator to supply power. This makes the size of battery pack smaller. This saves more fuel and is more preferable for far away travels. Example: LaFerrari.

Full hybrids or Series-Parallel: In this version of hybrid, as the name suggests, it mixes the power of both the above mentioned types. This allows the IC engine to take up the role of powering the vehicle completely or even let the motor be in charge fully and disconnect itself. With such options, the vehicle can operate at high efficiency, but at lower speeds it is usually the motor's job. This means a battery pack of bigger size and more work to manage the dual system. This category has a better performance and saves much more fuel than the alone series and parallel. Example: Toyota Prius. (Union of Concerned Scientists, 2015)

\section{Advantages of hybrid vehicles:}

Hybrid vehicles have increased capabilities and efficiency to maintain and manage the car. They react smartly to situations such as low battery power, by switching to the gasoline engine.

Using the electric motor on lower speeds and while driving around the city will result in huge decrease of amount paid for petrol/diesel filling.

When the car runs on the motor, there is zero consumption of fuel, which not only looks good in terms of budget but also provides to a cleaner and zero pollution safer environment. Unlike electric vehicle users who are at times left stranded with not being able to find an electric station for miles, hybrid users don't have to worry about such stations. The dual system switches smoothly from motor to the IC engine when it runs out of charge. While it runs on the engine, the regenerative braking system keeps charging the battery.

Maintenance of a hybrid car does not cost more than that of a regular gasoline car. In some cases, the routine checkup costs lower since motor is used more to run on. (Valleydrivingschool.com, 2018)

The hybrid variants are very silent vehicles when running on the motor. Hence, making it friendlier when driving around hospitals or schools.

\section{Disadvantages of hybrid vehicles:}




\section{Journal of Student Research}

Fourth Middle East College Student Research Conference, Muscat, Sultanate of Oman

Expensive and can cost up to a few thousands more than regular gasoline cars.

Battery power and charging might be an issue sometimes. Cases reported show that even leaving a light switch on for a night can drain the battery.

The silent moving of the car can also be a disadvantage, with cases being reported that some pedestrians had no idea about a car approaching, which can prove to be dangerous.

\section{LITERATURE REVIEW}

\section{Impact of Hybrid Cars on the Environment}

One of the major technologies found to have a significant contribution towards carbon emission reduction is the Hybrid Electric Vehicles or HEVs. This new type of vehicle is being praised for fuel efficiency and ultimately being environmental friendly. On the other hand, there are contradicting arguments regarding the impact of HEVs on the environment, which needs to be examined further. The environmental implications of HEVs can be better explored when observed in a smaller region where the data is more specific. Fuel prices in Oman are at a record high despite the fact that the country is a major global producer of petroleum products. As a result, a significant number of car owners in the country are shifting to HEVs. However, the shift towards HEVs is more on the economic than environmental position. In this regard, the discussion will explore how the shift towards HEVs impacts the environment specifically in Oman.

\section{Hybrid Cars vs. Traditional Cars}

There are two major questions that car consumers in Oman asks today when purchasing new vehicle, and that is whether the car is fuel efficient and environment friendly. Only HEVs have the highest potential for meeting the aforementioned two conditions. However, to compare conventional versus HEVs it is important to note pros and cons of each type. For HEVs, the advantage is higher mileage, high resale value, uses cleaner energy, but the tradeoff would be a higher price tag, higher maintenance cost, and no sport-tuned suspensions (Lexus, N.D.). On the other hand, conventional fuel cars command a lower price tag, better engine power, and low maintenance cost, but the drawbacks would be harmful emissions and low mileage (sterlingmccallford.com, 2019). A report published by Argonne in 2009 suggests that HEVs offer $90 \%$ reduction on petroleum energy use and $40-80 \%$ reduction on greenhouse gas emission (Elgowainy et al., 2009).

\section{Carbon Footprint and Environmental Impact in Oman}

In the case of Oman, the current environmental statistics suggests that carbon emission in the country is on a steady increase since the early discovery and production of oil and gas. From 1972 to 2011 there has been steep climb on the total CO2 emissions in Oman from 2,000 Gg to 40,000 Gg (Abdul-Wahab et al., 2015). Similarly, the study conducted by Yousif et al. (2017) shows a forecasted further increase in $\mathrm{CO} 2$ and greenhouse gas emissions of nearly 60 million tons in the country in the next decade. The major contributors of these emissions are continuous fuel combustion at 57.9, manufacturing at 24.2 and transportation at 12.3 (Yousif et al., 2017). The CO2 emitted by conventional cars in the country are added on both transportation and fuel combustion segments, which encompasses a much higher statistic when combined. In this regard, the Sultanate of Oman is seeing the potential of HEVs to counter the continuously increasing CO2 and GHG emissions in the country (McMurray, 2019).

In 2015, major car brands introduced HEVs in Oman such as Toyota Prius, which is spearheading the shift to HEVs across the Middle East (Times of Oman, 2016). Expectations of the car model 


\section{Journal of Student Research}

Fourth Middle East College Student Research Conference, Muscat, Sultanate of Oman

suggest that it is likely to reduce approximately 67 million tons of CO2 emission over the span of 20 years (Times of Oman, 2016). To date it is not certain how many of the HEVs were deployed in Oman, hence, the exact measure of its impact towards the country's CO2 emission reduction is still undetermined (CMS, 2018). There are several challenges observed in terms of further deployment of HEVs in Oman and one of them is the establishment of regulators that will oversee the operations encompassed by the introduction of HEVs in the country. One of the primary considerations is who would be responsible for the implementation and regulation of facilities such as charging stations, tariff fixing, and government registration and requirements (CMS, 2018).

\section{HYBRID ENGINES}

Hybrid cars have a distinct and a superior type of engine in comparison to the regular conventional engines. These hybrid engines intend to give us the best of both worlds: electric and gasoline. It utilizes two sources for getting power. The first source is the IC engine which is still the main source of power for the vehicle. The second source is an electric motor that is powered by the energy that is stored inside the battery of the car. The orthodox engine provides the required range and power to the car; meanwhile the electric motor derives its power from the engine and implements its environmental benefits.

When the car is started, the first thing to turn on is the battery and tandem with the electric motor. These components power up all the accessories needed in the car; which is why starting up the vehicle is silent since the IC engine has been activated yet. An exception to this rule is when the battery does not have enough energy to power up or the generator does not generate enough energy to power up the car, then the IC engine also starts up. At low speeds and with minimum effort in the vehicle, the motor is usually taking priority in accelerating and moving the vehicle forward. All the times, the car runs on electric motor, it consumes zero fuel and contributes to a safer environment by zero or no emissions produced in terms of exhaust.

When a higher acceleration is applied, the IC engine starts and takes over the work of the electric motor and now powers the car for the drive. The motor is also working with the IC engine but does not exert too much effort. It acts as an additional means of power provided in the IC engine. Recharging of batteries of the electric motor also is done by the engine with the help of a generator, to which power is directed. The motor, equivalently, offers extra torque and power, all the while providing a lower consumption of fuel.

Regenerative Braking is the process of converting energy that is wasted when the vehicle slows down into energy that is stored into the battery by with the aid of the electric motor (AFDC n.d.). This is one of the methods that is used to charge the battery. Every time the car applies breaks or comes to a halt, it releases kinetic energy. This energy is released usually by the breaks and turning of the wheels. The system then acquires this energy, and transforms it into electrical energy and sends it back to the batteries pack, where this is now stored for future utilization. In this way, it never completely runs out of charge. Although hybrid cars use this system of braking, the effectiveness of this braking system ultimately depends on the way the driver drives their vehicle. The most effective utilization of this system is by driving at constant speed and braking when necessary for maximum effectiveness (Toll 2019). 


\section{Hybrid Electric Vehicle}

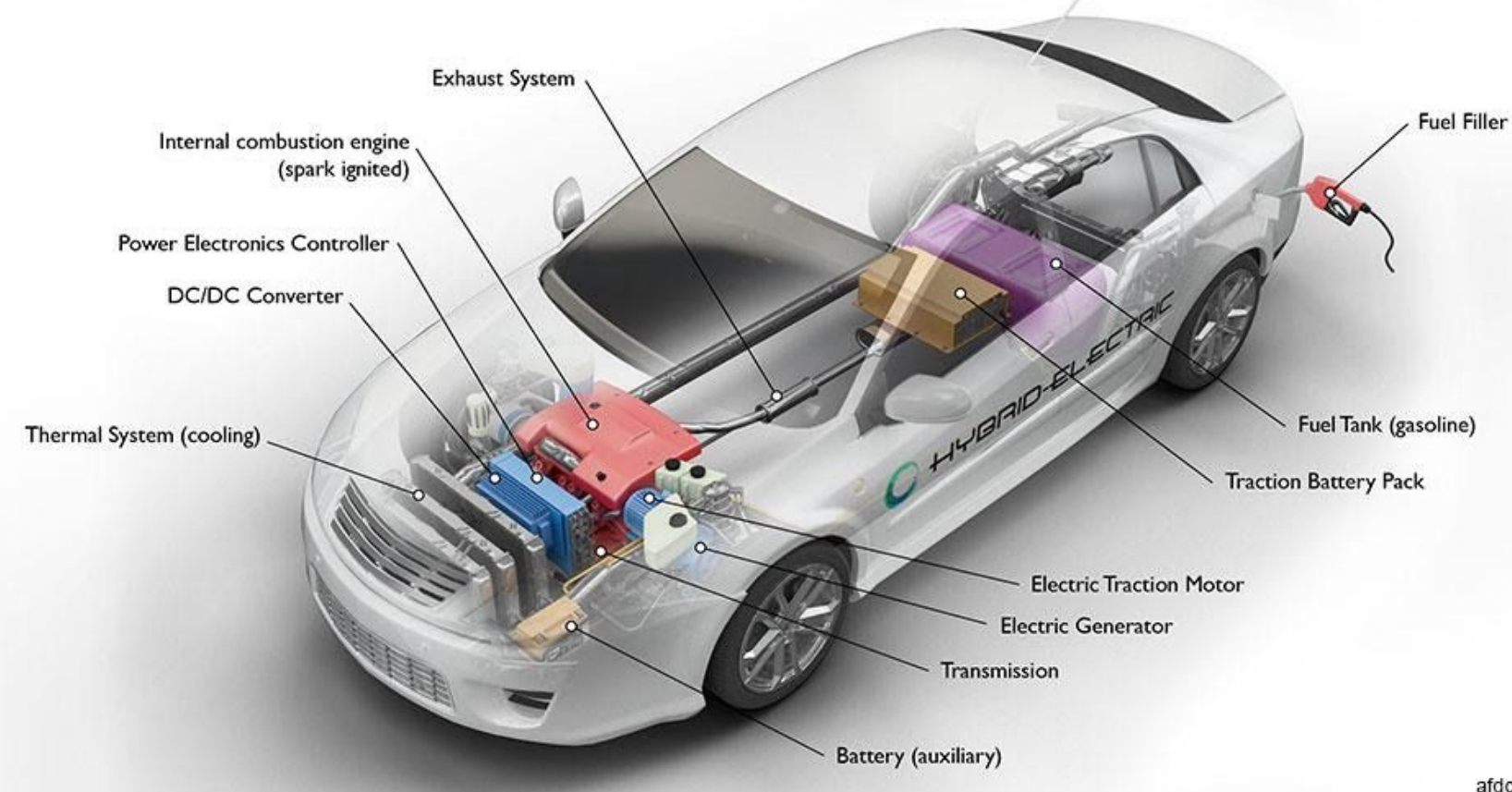

afdc.energy.gov

Figure 1. illustrates the basic structure of a Hybrid Electric Vehicle (AFDC n.d.)

\section{BATTERY AND ITS TYPES USED IN HYBRID VEHICLES}

The generator and motor of hybrid cars do not function alone. The energy that is produced needs a suitable location to be stored that if it is needed again. That is where the battery comes in place. According to the information that has been received when testing a hybrid vehicle, the battery stores the energy that has been produced and then that energy is used to power up the car and provide additional supporting energy for the car in conjunction with the IC engine. The batteries that are currently used are larger large and require additional space in the car. Traditional gasoline car engines have their batteries next to the engine of the car (Schleier 2016). Those are the leadacid batteries; which are found in almost every gasoline car. There are two more battery types that are used in hybrid cars, Nickel-metal hydride batteries and Lithium ion batteries.

\section{Nickel Metal Hydride}

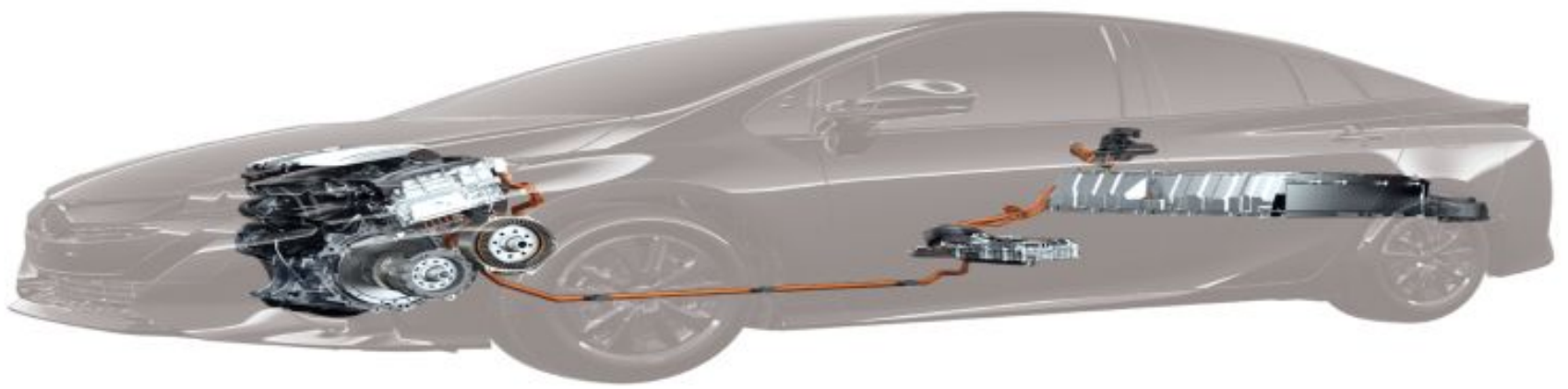

Figure 2. Skeletal example of how and where batteries are stored (Toyota 2016)

Nickel-metal Hydride; abbreviated to $\mathrm{NiMH}$, is the most common types of batteries currently being 


\section{Journal of Student Research}

Fourth Middle East College Student Research Conference, Muscat, Sultanate of Oman

used in hybrid cars. According to Sheller (2019), these batteries have been in use for some time. As seen in figure 3, these batteries are larger than the batteries are larger than lead-acid batteries, thus requiring more space. For this reason, the batteries are placed in the back of the car; either under the back seat of the car or in the boot of the car. The vehicles that had been tested have had their batteries under the back-row seats of the car with air ventilation holes covering the covering. When ask about the vents, the answer was to allow heat to leave the area and also allow the coolness of the vehicle to enter that area; basically, acting like a heat sink for the batteries under. This type of batteries has its advantages and disadvantages as well. According to Pettit (n.d.), one of the advantages of this type of battery is that a large life-span cycle as well as a predictable energy requirement.

Sheller (2019) agrees with this point, stating that "NiMH battery packs are less expensive and more predictable when it comes to performance". Battery University (n.d.) states that this battery is also easy and more linear to transport, since its transport is not under the jurisdiction of regulatory control. The most important advantage is that this type of batteries is environmentally friendly and is profitable if an entity wishes to recycle it. Moving to the disadvantages of this type of batteries, Sheller (2019) slightly disagrees about its safety towards the environment. It is stated that this type of battery has a relatively high level of toxicity. If by any chance this type of battery is disposed of in an improper manner, the NiMH component of the battery may harm the environment and human beings as well so proper care must be taken when recycling this type of batteries.

Pettit (n.d.) states that a disadvantage of this battery is its price. When asked about the price of hybrid cars in general, it was stated that these cars are more expensive than regular cars because of the additional components used in creating the car. This statement seems justified by Pettit's reason for the increase price of the battery. A disadvantage that has been stated by Green Ion Battery (n.d.) is the fact that it is true that this battery is able to discharge large amounts of energy, but a repeated discharge of large volumes of energy will cause the battery to degrade thus decreasing its life span. Battery University (n.d.) also shares this sentiment; stating that the battery is able to discharge a high load of currents, but its repeated discharge in that manner will be "reduce the battery's life cycle". It has been deduced that for this reason the Warranty of hybrid cars currently are 8 years or 160,000 kilometers distance covered whichever comes first. An article published by Motor One (2019) stated however that the time and distance has been increased to ten years and 150,000 miles.

\section{Lithium Ion}

Lithium Ion; shortened to Li-ion, batteries are batteries that have been used in many different electrical appliances, ranging from mobile phones to fully electric cars. This type of battery is yet to be used in hybrid vehicles although according to the information received, there is hope for using Li-ion battery to replace nickel-metal hydride batteries (Geisler 2010). There are advantages and disadvantages of Li-ion batteries in hybrid cars. These properties are based on fully electric vehicles. One of the important advantages is that is has a very high capacity potential for a smaller size. According to Battery University (n.d.), 1 liter of gasoline equates to approximately 12Kilowatts of electric energy. This is the case for fully electric cars.

Based on speculation, this means that if a hybrid car has a Li-Ion battery; it will be able store much more energy than NiMH batteries and even do more work thus requiring the IC engine to use less energy, although these are only speculations. Another advantage is that the battery has a lower selfdischarge rate. Compared to NiMH batteries, they have less than half the discharge rate (Battery University n.d.), meaning that the energy lost when the vehicle is not on is dramatically diminished. Another major advantage is that it has low maintenance bearing. The battery will rarely need to be replaced nor maintained; as long as it is in proper conditions. The point of maintenance leads to the disadvantage of Li-Ion battery. The battery is prone to aging and will age rapidly if it is not in the proper environment. 


\section{Journal of Student Research}

Fourth Middle East College Student Research Conference, Muscat, Sultanate of Oman

This effect cannot be terminated, but it can be slowed down by making sure that the battery is placed in cool area. Places where the weather is exceptionally hot during the summer; for example, an area where the temperature exceeds 40 degrees Celsius, will not bode well to the battery's life span. The battery also requires circuit protection to prevent it from sending a large voltage throughout the circuit in cause any provocation happens. The most detrimental drawback is that it is extremely expensive to manufacture. Sheller (2019) states that a battery pack may reach up to 5,000 US Dollars. In hybrid vehicles this would increase the base price of the vehicle dramatically. Despite the drawbacks, Lithium ion batteries for hybrid cars are still a work in progress and may be implemented when alternatives for it are discovered.

\section{A CASE STUDY: TOYOTA PRIUS}

The first hybrid car to be produced in mass amounts, in the world is a Toyota Prius. According to a report published in September 2019, Carmax ranked Toyota Prius on spot number one among the 15 best hybrid cars.

A $1.3 \mathrm{kWh}$ battery is contained within the Prius, storing the energy produced and providing it to boost the car, when needed. With bigger battery packs being expensive and heavier, the much affordable Prius doesn't hold it. Being a series-parallel, the car can turn its 1.8L IC engine off and completely rely on the $53 \mathrm{~kW}$ electric motor, but only at low speeds. The small battery packs in the Prius, along with being light weight and less expensive, has an advantage of quickly gaining back the lost power with the help of regenerative breaking. When these batteries are running low on power, in places where, there are not much brakes being applied and the speed is constant, the engine stays switched on to not only power the vehicle for the drive, but as well recharge the batteries. After this, when full acceleration is applied, the motor and the engine work together simultaneously, but maintaining less power.

This provides the car a high intensity boost. Both the engine and the motor are present under the bonnet of the Prius. The motor has been separated into two different motors - first motor generator (MG1) and second motor generator (MG2). The MG1 is used as an initiation motor; it connects with any extra power from the petrol engine to utilize it then to charge the batteries which are situated under the backseat. MG2 that is the main motor, it powers the car in situations of initiation, reversing and at low speeds. It later acts as a generator, trapping any power that is lost when brakes are applied. The MG1 and MG2 have a continuous variable transmission (CVT), which makes sure of the level of motor voltage.

The Toyota Prius expends 3.4L per 100 kilometers. According to sources, the company claims that these batteries are designed in a manner, in which the battery tends to charge and discharge for a period of time. They have hence, a warranty that lasts up to eight years or a hundred and sixty thousand kilometers. 


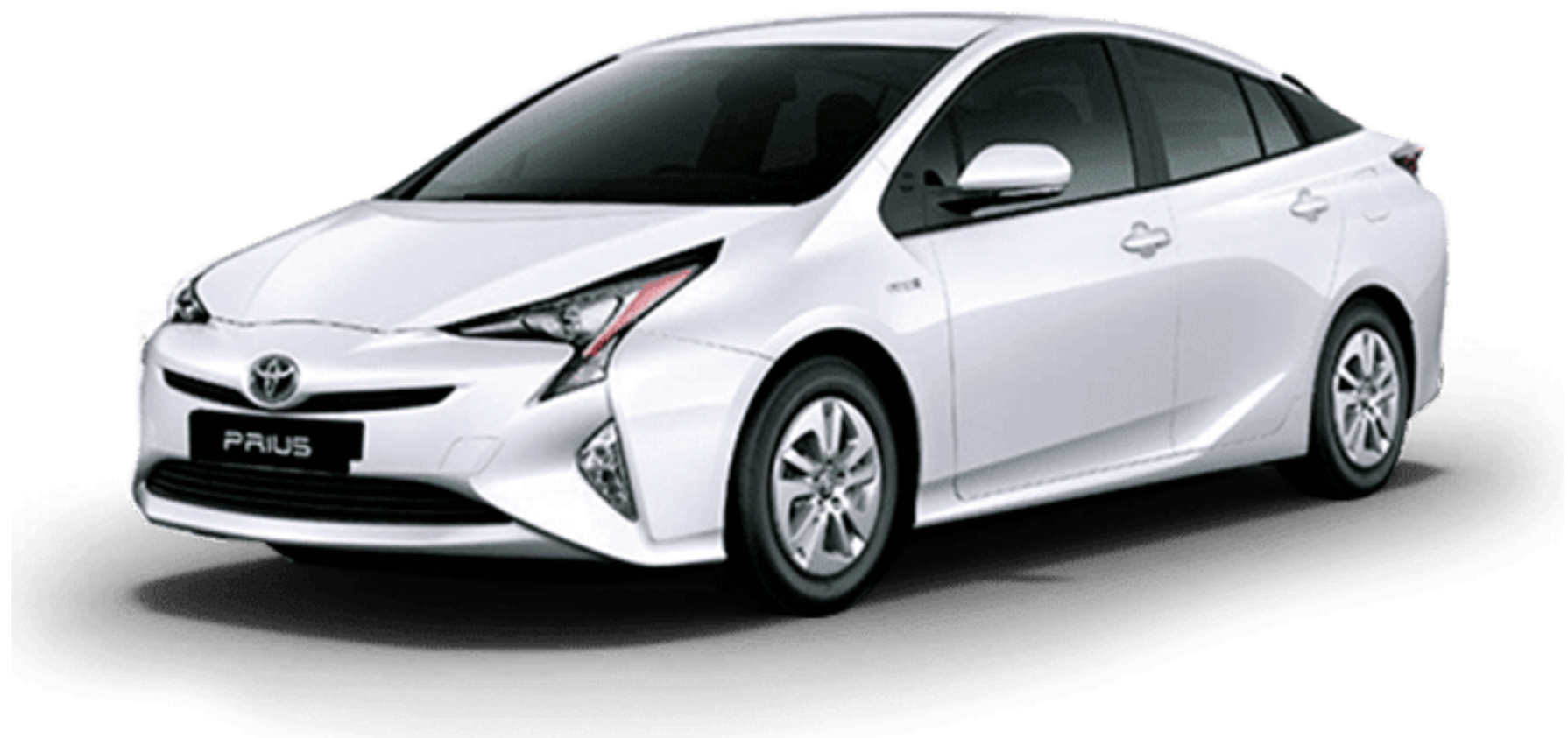

Figure 3. Toyota Prius.

Figure 4. The IC engine and the motor in the front, powering the batteries present in the backside.

\section{INFORMATION COLLECTED THROUGH PRIMARY SOURCES}

\section{Interview}

An interview was carried out with a highly reputed and well known company producing hybrid car. This is a fully trusted source and hence it improved the understanding of said vehicles.

A hybrid vehicle is a vehicle that uses 2 sources of power to operate. The most common type of hybrid vehicles that are seen are vehicles that uses an Internal Combustion engine and an Electric Motor that is charged by a battery that is inside the car. The car operates using both methods. When staring up the car, the electric motor starts running and takes priority in driving unless a certain speed is exceeded or depending on how hard or fast the driver accelerates, then it switches priority to the IC engine; as in it does most of the work of pushing or applying force to the car. When the vehicle is driven, both the engine and the motor are functioning together with one doing more work depending on how the user drives. Because of the system in hybrid vehicles, the vehicle will consumes less gasoline. An example would be: if a regular gasoline car drive 20kilometers with 7 liters of gasoline, a hybrid vehicle would be able to drive 29kilometers with the same amount of gasoline.

From an environmental perspective, this means that a hybrid car would consume less gas and would also produce fewer toxic fumes due to it consuming less gas. A feature of hybrid cars is that 


\section{Journal of Student Research}

Fourth Middle East College Student Research Conference, Muscat, Sultanate of Oman

if the car idles; as in stops moving, the IC engine turns off and the electric motor works. This comes in especially handy in areas that are congested in traffic since when idling but gasoline cars will still consume gasoline. This has been tested in many cars and cars with advanced user interfaces, it indicates that even when the car is idle, it consumes gasoline. In hybrid cars, if the car is idle or the car is moving very slowly, the electric motor takes control while the IC engine shuts off until the speed is picked up again. This ultimately means that hybrid in congested and slow areas will reduce pollution significantly due to this feature.

The batteries that are used in hybrid cars are nickel metal battery or nickel-metal hydride battery. It is a large battery that is placed under the back seat of the car. Under the back seats, there are vents act as a heat sink for the battery. This is the battery that provides power to the electric motor and in turn also gets charged by the electric motor. The battery is placed in that area due to its size, since it is a large battery. The placement also acts as weight distribution technique since if the battery is placed in the traditional area; near the engine for gasoline cars, the car would be heavy from the weight and would require extra force to move the car thus requiring additional energy thus consuming more gas. While in the back seat, it distributes the weight throughout the car causing it to consume less energy. The nickel metal battery; compared to the lead-acid battery found in gasoline cars, is more environmentally friendly. Plans for hybrid cars include the nickel battery with a lithium ion battery, due to its smaller size, lighter weight and its capability to store a larger amount of energy. This plan has been halted partially due to lithium ion's battery prices being far too expensive. The least expensive and most common batteries are lead-acid, then followed by nickel-metal hydride and lithium ion being the most expensive, which is why most hybrid cars currently have nickel-metal batteries.

The overall prices of hybrid vehicles are slightly more expensive than their gasoline-car counterpart. This is because the materials used for creating hybrid cars are slightly more expensive than traditional gasoline cars; the main thing being the battery, its components, the electric motors and its components as well. The difference of costs is observed have a $10 \%$ to $15 \%$ discrepancy between them; for example: a gasoline car will be priced at OMR 10,000 base price, while a hybrid variant of that same car would be OMR 11,500 base price. Because of this increase in price, customers are often discouraged from purchasing hybrid vehicles. Another fear is that the maintenance of hybrid vehicles might be deemed too difficult and expensive. Based on what was discovered, these two issues have a solution.

The first issue being the increase in price, the materials used might be more expensive, but are more environmentally friendly since hybrid cars naturally emit fewer toxic fumes due to the decrease work of the IC engine. In addition to that, hybrid cars consume less fuel, as was mentioned previously. It is true that the purchase price will be higher, but considering the future, the amount of money spent on refilling the vehicle would be significantly less and hence the extra price would get balanced out there. The other issue regarding maintenance, it has been observed that fixing a gasoline vehicle and hybrid vehicles are almost the same. Despite having different components, maintaining and repairing the vehicles are almost the same in terms of effort and money-wise. As mentioned before, if there's a larger profit and reception, the battery component that will be used will be of higher quality. Considering the overall success of hybrid cars, that goal seems viable. Toyota introduced the hybrid car Toyota Prius initially. Due to its success, Toyota has introduced several Hybrid cars. Starting with Toyota Camry, Toyota Corolla and Toyota RAV4. This means that hybrid car's interests among people are increasing and with the increase of hybrid vehicles, the amount of pollution that will be emitted from vehicles will be reduced.

Hybrid vehicles act as the gateway from gasoline car to fully electrically charged cars; although fully electric cars don't seem like a viable; at least in the time being it isn't. In European Union, there is a limit on how much metric ton of Carbon Dioxide a hybrid car should emit. Despite the imposed limit, hybrid cars were able to produce much less than the imposed limit and are witnessed to attempt to reduce the amount even further per vehicle. Hence proving that putting hybrid cars into use, would be an overall advantage for the individuals, as well as for the 
environment.

\section{Survey}

A survey was created using online tools and a few relevant questions were put up. Up to 36 responses were received and registered. Given below are the results of the conducted survey:

Figure 5. Survey results.

In the above question, $88 \%$ agreed to the fact that there has been a rise in air pollution due to road transportation. On the other hand, $11 \%$ of them did not agree to it. As the majority agrees to it, it can be considered that this is a serious issue being caused due to increasing petrol/diesel running automobiles.

\section{Figure 6. Survey results.}

The next question has the details related to how much an individual spends per month on refilling their car either with fuel. Around $66 \%$ of the respondents said the amount would be between $50-$ 60 OMR, 19\% chose the range of $60-70$ OMR and 13\% fell in the range of more than 70 OMR. These rates are alarming, considering the economic conditions, such huge amounts being spent just on fuel, will be a burden on lot of families to be able to manage their budgets.

Figure 7. Survey results.

On asking if they were knew what hybrid cars were, surprisingly there were $16 \%$ of people who were not aware of it and $27 \%$ who had some idea about it but did not know what exactly they were. $55 \%$ knew the concept of hybrid cars. This shows that there are people with less or no knowledge on this topic at all and hence need to be made aware.

\section{RESULTS}

The topic of hybrid cars was keenly inspected. The major parts of it were broken down and critically analyzed. The study produced results that could positively affect everyone involved. With respect to different aspects, the results reviewed are as produced below:

\section{Environmental Impact}

The first and one of the most important result of implementing hybrid cars usage, is the environmental factor. According to the survey conducted among 36 people, $88 \%$ of the respondents agreed that air pollution has increased due to the automobiles on road. Cars driven in the city, when they run on low speeds, or are stuck in heavy traffic, the regular gasoline cars keep the engine running which at the same time exhales fumes causing increasing air pollution on extreme levels. The same situation when applied to hybrid cars, they smartly switch to the electric motor, causing zero fuel consumption and zero air pollution. This not only contributes to saving money but also to a greener and healthier environment..

\section{Money Saver}

The survey shows that on an average around $66 \%$ of people agreed to spending between $50-60$ 


\section{Journal of Student Research}

Fourth Middle East College Student Research Conference, Muscat, Sultanate of Oman

OMR per month just on petrol/diesel. Going by the figure 60, that is 720 OMR per year. And people that fall into the more than 70 category; that would sum up to a whopping 960 OMR per year. For most of the people, 960 to 1000 OMR per year is a huge amount to be wasted just for refilling cars. With hybrid vehicles in place, this number is sure to come down by a few hundreds, saving money in the long term.

\section{Safety}

Referring to the report issued by Insurance Institute for Highway Safety, it claimed that in crash tests, hybrid cars performed better than the regular gas cars. The data showed that the people within a hybrid vehicle would be $25 \%$ less injured than a same standard gasoline vehicle, as well as the driver's death rate showed a reduction when it came to hybrid models. The reason the hybrid models executed well in the crash tests was due to the heavy weight they carry. According to the reports, these models are $10 \%$ more heavier than the regular gasoline cars, and hence when they crash, the heavier vehicle tends to have a greater impact on the light weighted gasoline counterparts and pushes it backwards. (Edgerton, 2011) For example, the hybrid variant of Accord is $217 \mathrm{~kg}$ 's more than the standard Accord.

A lot of news is surrounded around the topic of how Lithium Ion battery used in these vehicles could prove dangerous by getting overheated and may also catch fire. Companies manufacturing and producing hybrid cars have stated that it takes a long process to modify and tame the li-ion batteries to make it safer and runnable for years (Tajitsu, 2016). Along with the newly modified and now much safer lithium ion batteries, Tesla Motors mentioned that they developed a cooling system and have also created sensors and fuses up to three layers of protection to safeguard the batteries from overcharging. The role of the fuses and the sensors is to immediately disengage the battery in use, when there is a rise in the temperature, a roll-over or an unexpected impact. From a safety point of view, the makers decided to use a number of smaller batteries in comparison to a few large ones, since the energy stored will also be in small amounts and enclosed within its own steel cases, it will also prove safer.(Bullis, 2006)

\section{DISCUSSION}

The main objective of this research is to analyze Hybrid-Electric Vehicles (HEV) and their components and justify how these vehicles are less harmful than gasoline cars to the environment. This is done by analyzing and conspicuously explaining how an HEV works, its characteristics and the components that differentiate it between traditional gasoline. The result after testing the vehicles and researching and understanding its components is that HEV does is indeed less harmful to the environment due to it consuming less gasoline and because the components; mainly the battery and motor, are naturally built to be less impactful to the environment.

This research also aims to encourage consumers into buying HEV. If the number of total hybrid vehicles increase and the total number of gasoline vehicle decrease, the total amount of pollution caused by vehicles would drastically decrease due to the total consumption of gasoline decreasing as large amounts of gasoline won't be needed to fulfill the needs of hybrid vehicles. This ultimately reduces environmental pollution caused by vehicles. Along with the reduction of pollution, the amount of money saved of fuel refilling's could be turn out to be helpful for most of the individuals, who are struggling with balancing their budget.

\section{CONCLUSION}

All the above topics, which have been analytically studied, it concludes that the hybrid vehicles prove to be more eco-friendly and safer for the environment than the IC engine vehicles. With increasing production of hybrid variants, batteries are being planned and designed in way that extends its life as well as provides the ability of recycling. This all in all, turns to be safer, healthier 


\section{Journal of Student Research}

Fourth Middle East College Student Research Conference, Muscat, Sultanate of Oman

and also a money saver package, saving you a fine amount spent on fuel. Investigation into other vitality sources, for example, power devices and sustainable powers make the future look more splendid for hybrid vehicles.

\section{RECCOMENDATIONS}

Many people have the conception of hybrid vehicles being a lot more expensive than the regular gasoline vehicles. The truth in fact, is that the hybrid types cost only a very few more thousands than the gasoline types of the same model. For example; the Hyundai Sonata Hybrid costs \$26,000, whereas the gasoline counterpart costs $\$ 22,000$. In the long run, these few extra thousands will cover up the huge amount spent on fuel yearly. It was also witnessed that the EU is providing incentives for people who use fully electric cars, such as reduced taxes and other similar traits. A similar trait can be introduced and implemented in GCC counties to encourage the purchase of hybrid vehicles, like for example reduced gas rates per liters for certified hybrid cars. Due to the nature of electric cars, it doesn't seem like a viable solution; at least in GCC to implement them since they are the most environmentally friendly vehicles due to the exclusion of an IC engine. The reasons behind this are: electric cars don't cover enough millage without needing to be recharged.

Based on experiments conducted, the most distance that an electric car was able to attain by driving in specific conditions was approximately 300kilometers without needing to charge the car. Another reason is that there are not enough charging stations. Until that reality comes into fruition, hybrid vehicles are deemed to be the most viable solution to reduce pollution; at least in the GCC.

\section{REFERENCES}

Abdul-Wahab, S., Charabi, Y., Al-Rawas, G., Al-Maamari, R., Gastli, A. and Chan, K. (2015). Greenhouse gas (GHG) emissions in the Sultanate of Oman. Greenhouse Gases: Science and Technology, 5(3), pp.339-346.

Alternative Fuels Data Center (AFDC) (n.d.) How do Hybrid Cars work [online] available from <https://afdc.energy.gov/vehicles/how-do-hybrid-electric-cars-work> [23 November 2019]

Amoatey, P. and Sulaiman, H. (2017). Options for Greenhouse Gas Mitigation Strategies for Road Transportation in Oman. American Journal of Climate Change, [online] 2017(6), pp.217-229. Available at: https://www.scirp.org/pdf/AJCC_2017041915493677.pdf [Accessed 29 Nov. 2019].

Archer, J. (2011). New Study Says Hybrids Are Safer. [online] autotrader. Available at: https://www.autotrader.com/car-news/new-study-says-hybrids-are-safer-136321 [Accessed 26 Nov. 2019].

Argonne (2009). Well-to-Wheels Energy Use and Greenhouse Gas Emissions Analysis of Plug-in Hybrid Electric Vehicles. Energy Systems Division. [online] Oak Ridge, TN: U.S. Department of Energy. Available at: https://publications.anl.gov/anlpubs/2009/03/63740.pdf [Accessed 29 Nov. 2019].

Auto Training Center (n.d.) 'Importance: Car Batteries' [online] available November 2019]

Battery University (n.d.) Can Lead Batteries Compete in Modern Times [online] available from $<$ https://batteryuniversity.com/learn/archive/can the lead_acid battery_compete in modern times $>$ [23 November 2019]

Battery University (n.d.) Elevating Self-Discharge [online] available from $<$ https://batteryuniversity.com/learn/article/elevating_self_discharge > [23 November 2019]

Battery University (n.d.) Is Li-Ion the Solution for Electric Cars [online] available from 


\section{Journal of Student Research}

Fourth Middle East College Student Research Conference, Muscat, Sultanate of Oman

< https://batteryuniversity.com/learn/archive/is_li_ion the solution for the electric_vehicle $>$ [23 November 2019]

Battery University (n.d.) What's the Best Batery [online] available from $<$ https://batteryuniversity.com/learn/archive/whats_the_best_battery> [23 November 2019]

Bullis, K. (2006). Are Lithium-Ion Electric Cars Safe? [online] MIT Technology Review. Available at: https://www.technologyreview.com/s/406201/are-lithium-ion-electric-cars-safe/ [Accessed 28 Nov. 2019].

CarMax (2019). 15 Best Hybrid Cars: Ranked. [online] CarMax. Available at:

https://www.carmax.com/articles/best-hybrid-cars-ranking [Accessed 28 Nov. 2019].

CMS (2018). Electric Vehicles in Oman | Developments that Impact the EV Industry. [online] Cms.law. Available at: https://cms.law/en/int/expert-guides/cms-expert-guide-to-electricvehicles/oman [Accessed 29 Nov. 2019].

drive.com.au (2012). How a Hybrid Engine Works | Drive.com.au. YouTube. Available at: https://www.youtube.com/watch?v=m2qvGJwTuBo\&t=4s [Accessed 25 Nov. 2019].

Drive.com.au (2018). How a Hybrid Car Works, Hybrid Engines Explained | Drive.com.au. YouTube. Available at: https://www.youtube.com/watch?v=T9Dk_2_XL7k [Accessed 27 Nov. 2019].

Drivingfast.net. (2018). Hybrid car technology - Drivingfast.net. [online] Available at: https://drivingfast.net/hybrid-car-technology/.

Edgerton, J. (2011). Crash test: Hybrids safer than other cars. [online] Cbsnews.com. Available at: https://www.cbsnews.com/news/crash-test-hybrids-safer-than-other-cars/ [Accessed 28 Nov. 2019].

Geisler, K. How Stuff Works (2010) Lithium Ion Batteries Improve Hybrids [online] available from <https://auto.howstuffworks.com/lithium-ion-batteries-improve-hybrids.htm> [23 November 2019]

Green Ion battery (2016) Nickel based Batteries: Advantages and Disadvantages [online] available from

$<$ http://greenionbattery.com/nickel-based-batteries-advantages-and-disadvantages-of-nickel-metalhydride-nimh/> [23 November 2019]

Lampton, C. How Stuff Works (n.d.) How Regenerative Breaking Works [online] available from $<$ https://auto.howstuffworks.com/auto-parts/brakes/brake-types/regenerative-braking1.htm> [23 November 2019]

McMurray, D. (2019). Is Oman Ready To Make The Transition To Smart, Electric, Low-Carbon Mobility? | CleanTechnica. [online] CleanTechnica. Available at:

https://cleantechnica.com/2019/01/13/is-oman-ready-to-make-the-transition-to-smart-electric-lowcarbon-mobility/ [Accessed 29 Nov. 2019].

Michał Krzyżanowski, Kuna-Dibbert, B. and Jürgen Schneider (2005). Health effects of transportrelated air pollution. Copenhagen: World Health Organization Europe.

Pettit, C. Cobalt Institution (n.d.) Nickel-metal Hydride Batteries [online] available from < https://www.cobaltinstitute.org/nickel-metal-hydride-batteries.html> [23 November 2019]

Schleier, K. Click Mechanic (2016) Where is My Car Battery Located [online] available from < https://www.clickmechanic.com/blog/where-is-my-car-battery-located/> [23 November 2019] 


\section{Journal of Student Research}

Fourth Middle East College Student Research Conference, Muscat, Sultanate of Oman

Sheller, D. The Hybrid Geek (2019) 3 Types of Hybrid Batteries [online] available from <https://www.thehybridgeek.com/3-types-of-hybrid-batteries/> [23 November 2019]

Smith, C (2019) 'Toyota Extends Hybrid Battery Warranty to 10 Years or 150,000 Miles' Motor One [online] 10 October. Available from

<https://www.motor1.com/news/375760/toyota-extends-hybrid-battery-warranty/> [23 November 2019]

sterlingmccallford.com (2019). Gasoline vs Hybrid Cars. [online] Sterling McCall Lexus Clear Lake. Available at: https://www.sterlingmccallford.com/hybrid-versus-gas-car.html [Accessed 29 Nov. 2019].

Tajitsu, N. (2016). Warming to lithium-ion, Toyota charges up its battery options. [online] U.S. Available at:

https://www.reuters.com/article/us-toyota-batteries/warming-to-lithium-ion-toyota-charges-up-itsbattery-options-idUSKBN12U0ZH [Accessed 28 Nov. 2019].

Times of Oman (2016). Toyota hybrid car sales cross nine millions mark. [online] Pressreader.com. Available at: https://www.pressreader.com/oman/times-of-oman/20160808/281857232922744 [Accessed 29 Nov. 2019].

Toll, M. Electrek (2018) Regenerative Braking: How it Works and is it Worth It [online] available from <https://electrek.co/2018/04/24/regenerative-braking-how-it-works/> [23 November 2019]

Toyota (2016) Advancement of Toyota Hybrid Systems [online] available from $<$ from< https://www.autotrainingcentre.com/blog/importance-car-batteries/> [23November 2019]

https://global.toyota/en/powertrain/ths/> [23November 2019]

Union of Concerned Scientists. (2015). Series vs Parallel vs Series/Parallel Drivetrains. [online] Available at: https://www.ucsusa.org/resources/all-about-drivetrains [Accessed 27 Nov. 2019].

Valleydrivingschool.com. (2018). Hybrid vs Traditional Combustion Engines. [online] Available at: https://www.valleydrivingschool.com/blog/main/hybrid-vs-traditional-combustion-engines [Accessed 27 Nov. 2019].

Yousif, J., Alattar, N. and Fekihal, M. (2017). Forecasting Models Based CO2 Emission for Sultanate of Oman. International Journal of Applied Engineering Research, [online] 12(1), pp.95-100. Available at: https://www.ripublication.com/ijaer17/ijaerv12n1_12.pdf [Accessed 29 Nov. 2019]. 